\title{
Surface Ships under Complicated Electromagnetic Environment Electronic Warfare Training Mode Research
}

\author{
Xinjie Zhang ${ }^{1, a}$ and jie Yue ${ }^{2, b}$ \\ ${ }^{1}$ Department of Surface Ship Command, Dalian Naval Academy, Dalian, 116018, China \\ ${ }^{2}$ Unit 91278 Dalian, 116018, China \\ a446982051@qq.com, bgku94852@tom.com
}

\begin{abstract}
Keywords: Complex electromagnetic environment, Electronic warfare, Training mode, Effect evaluation
\end{abstract}

\begin{abstract}
Naval electronic warfare training mode of warship electronic warfare training towards scientific, standardized and institutionalized development plays a guiding role. Based on the analysis of warship electronic warfare training facing the problems, difficulties, and needs on the basis of, for the construction of the complex electromagnetic environment is suitable for me warship electronic warfare training mode is analyzed and the research, hope for surface ships under complicated electromagnetic environment provide a basis for ecm training, also lay the foundation for follow-up study.
\end{abstract}

\section{Introduction}

In modern military field, the new technological revolution promoted the rise of the new military revolution, the complex electromagnetic environment more intensified both sides strength change, at the same time increase the uncertainty of the war. My main battle rival attaches great importance to surface ship information equipment development, operational use, especially through various means to improve the level of combat training. Faced with such serious situation, I must solve the level of training and information operations does not match the status quo, strengthen the complicated electromagnetic environment I surface warship electronic warfare training mode research, in order to achieve rapid ascension, surface ships training under complicated electromagnetic environment pushed forward.

\section{Surface Warship Electronic Warfare Training New Problems under Complicated Electromagnetic Environment}

Wrong Understanding of Training Essential Connotation. At present, the ship unit is to develop complex electromagnetic environment of training, but because of the lack of training in complex electromagnetic environment correctly identify the essential connotation, in practice there are a lot of bias problem, directly affected the further training and development. One is one-sided equates training under complicated electromagnetic environment for a simple electronic warfare professional technical training, that is electronic reconnaissance and confrontation, the department of electronic warfare is matter, not over raising troops combat ability and training as a whole. Second, no matter what training, also no matter what training is as the name "complex electromagnetic environment, the real may face the future of the complex battlefield electromagnetic environment research is not deep false ${ }^{[1]}$.

Build Realistic Simulation of Battlefield Electromagnetic Environment. One is to build practical naval battle field electromagnetic environment model. To build the practical naval battle field model of complex electromagnetic environment must be based on reasonable and practical. Because we are now on the enemy's electronic jamming radiation characteristics is difficult to grasp, more difficult to accurately get ready for the performance parameters of the weapons, the complex electromagnetic environment are often constructed cannot reach lifelike effect; Secondly, the existing methods cannot meet the requirements. Technical limitations has a great influence on 
the building, the existing equipment is difficult to reflect the effect of actual naval battle field electromagnetic environment ${ }^{[2]}$; Three is "electromagnetic environment" contains a "live" operational ideas, the construction of electromagnetic environment is "technical environment" and "tactical environment" unity, it is not enough to simulate "technical environment". How to quantify the electromagnetic environment, how to combat task Settings for different combat background, different electromagnetic environment, these are all in building the practical difficulties faced in the simulation of battlefield electromagnetic environment.

Training Under Complicated Electromagnetic Environment to Organize the Implementation of Difficult. Training of ships under the complex electromagnetic environment is the importance of advancing ships under the condition of informatization training methods, training in how to reflect the complex electromagnetic environment on the impact, how to solve the key technical parameters of confidentiality issues, how to set up training topic, how to handle the relationship with the existing training outline in the training content, how to deal with all levels of training in complex electromagnetic environment requirements and so on, these are all ships training under complicated electromagnetic environment of new problems.

Training Effect Evaluation Is Difficult Under Complicated Electromagnetic Environment. Ships in training evaluation assessment is a very important link, the purpose is to check the training conditions, inspection training effect and improve the quality of training. Battlefield electromagnetic environment is imperceptible to the touch, is invisible to the main of weapons and equipment availability, completeness of the construction of the battlefield, the battlefield awareness, command and control stability and the accuracy of operation effectiveness, etc have important influence, if still use previous training assessment evaluation methods, to combat training misleading ${ }^{[3]}$.

\section{Surface Ships under Complicated Electromagnetic Environment Electronic Warfare Training Demand Analysis}

The Theory Instruction Need. Naval electronic warfare training gradually from a single system, simple mode of training to training under complicated electromagnetic environment. In the process of transformation, we must first concept of personnel organization and the trainees from mechanized war under the condition of the transition of the training to the information-based war under the condition of electronic warfare training; Secondly we must also rely on the existing equipment and establishment system, the construction of complex electromagnetic environment generated method, meet the demand of training to build that could satisfy the requirement of actual combat training content; And synchronization and form a complete set of evaluation mechanism and security conditions. All these changes and construction for I ship training is a new subject, in the practice process to the basic theory of complex electromagnetic environment, complex electromagnetic environment simulation and theory construction, electronic warfare training under complicated electromagnetic environment demand theory, assessment of electronic warfare training under complicated electromagnetic environment appraisal theory support.

Surface Ships Demand for Training Environment for Ecm Training. (1)Ew equipment demand for training the basic electromagnetic environment

Training required for main battle rival electromagnetic radiation environment setting is one of the important factors restricting the training effect is good or bad. As the field to continue to expand, means constantly, at present, new equipment are listed in the surface ships. Need to build a more realistic training environment, America, Japan, Taiwan and other main rival of the equipment system of technical parameters, technical and tactical use based on, build the electromagnetic radiation environment needed equipment training [4].

(2)Trainees demand for training environment

One is the trainees training need simulation of naval battle environment. For staff to create "immersive" naval battle field environment, thus exercise personnel fighting will, combat style and psychology to bear ability; Second, the trainees training need force posture environment. In order to further increase the antagonism and of training and actual combat of closeness, needs through 
effective simulation to generate more realistic dynamic force posture; Three is the trainees training need realistic complex electromagnetic environment. Make training workers earned in a more realistic combat environment, improve their position in developing information operations at sea under the complex electromagnetic environment adaptability; Fourth, trainees training need good institutional environment. Create a regularization, institutionalization, standardization, scientific training system environment and incentive system is my ship unit under the condition of information technology to carry out the training.

(3)Complex electromagnetic environment building requirements

Surface ships to carry out the training, need to surface vessels may face on the informationization naval battle field to simulate the complex electromagnetic environment and generate as much as possible, to construct lifelike enemy land, air, water and underwater force platform the electromagnetic radiation signals, and our radar, communication and other radiation environment[5]. Can through the use of simulation in practical training equipment and we will be built live-fire training requirements complex electromagnetic environment, its building ideas as shown in Fig. 1.

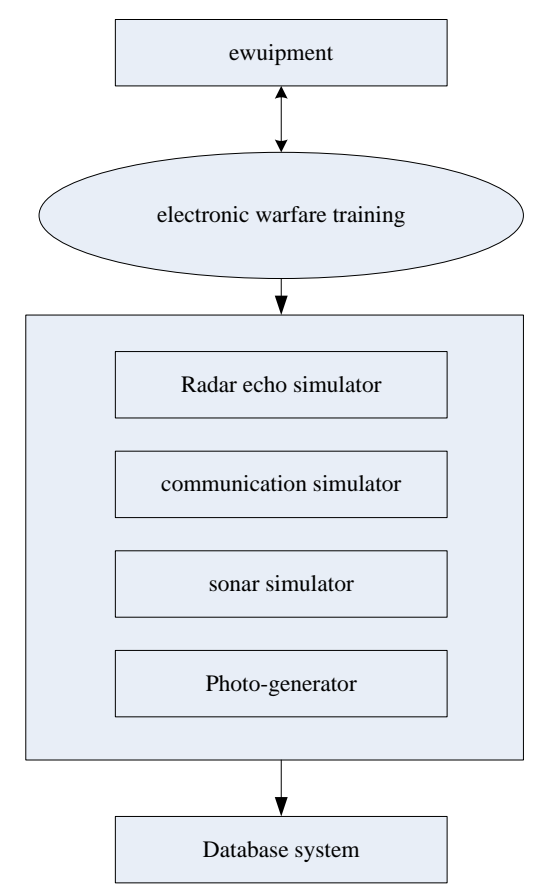

Figure 1. complicated electromagnetic environment conceive

Training Effect Evaluation Needs. Ships tactical training effect evaluation compared with other weapon system evaluation of training effect with the scene to direct the training result is difficult to determine, involves many factors, the evaluation process more complicated, etc. Especially the training under complicated electromagnetic environment, the parameters of the need to record more, after training needs assessment and calculation of factors is more complex, in varying degrees under the complex electromagnetic environment of the same standard of evaluation is inappropriate. Must be based on complex electromagnetic environment, therefore, the practice of training, tactical training in line with the actual research and develop new training examination evaluation system, and the construction of the corresponding record, playback, and evaluation of security conditions.

Special Training Facility Requirements. Combining the practice, it is necessary to develop dedicated training facilities for training, through the computer simulation technology to establish a realistic virtual radiation environment and environmental force posture or half physical training equipment to provide more effective training for the ship fee than the means of training. Need special training simulation facilities can be divided into: the battlefield electromagnetic environment simulation system, combat training simulation system, major equipment form a complete set of training simulation system. To improve the quality of training, training facilities for 
the construction of the long-term, need to development in the direction of seriation, standardization, and modular.

Professional Talent Demand. As the future combat of warship under complicated electromagnetic environment improvement of operational capability, and a rapid increase in informatization degree of warship equipment itself ships training on organization and training of security personnel more new requirements, including: 1) the corresponding hardware and software aspects of talent; 2) the new organization and command respect person; 3) electronic information technology talents.

\section{Surface Ships under Complicated Electromagnetic Environment Electronic Warfare Training Mode Building}

The Principle of Surface Warship Electronic Warfare Training under Complicated Electromagnetic Environment. (1) The theory guide of bold practice principles

Theories is the precondition of all military operations and training, does not have the right theory, there would be no scientific and effective practice. Only through practice can continuously explore perfect theory, the correction theory, form the virtuous circle of theory and practice, has general guide meaning to eventually form surface ships under the complex electromagnetic environment of electronic warfare training of military theory, driving to the deepening of surface warship electronic warfare training under complicated electromagnetic environment [6].

(2) Technology combination of the principle of system optimization

Ew professional technical training is the foundation, electronic warfare operational application training is the key, in training must pay attention to the combination of professional technical and operational application. Through professional and technical training, can make the officers and soldiers clear rival technology characteristics of electronic reconnaissance, such as targeted to electromagnetic spectrum control, spoofing, electronic camouflage, electronic jamming and other technical means, reduce the enemy electromagnetic combat effectiveness. For operational application training of electronic warfare system, through the power of the scientific and reasonable configuration and concerted action, overall improve system's ability to adapt to the complex electromagnetic environment.

(3) Outstanding against the principle of the training war

"Training war" is the eternal law of military training, is also an inevitable choice for comprehensively enhance battle effectiveness. Future war is an information-based war, the outstanding characteristic of the battlefield is complex electromagnetic environment, it is need to adhere to the "war in a complex electromagnetic environment, practice" by the complex electromagnetic environment of ideas, outstanding training, implementation "soldiers how to practice, how do I call you have" goal.

\section{Surface Ships under Complicated Electromagnetic Environment Object and Contents of the Electronic Warfare Training}

1. Surface Warship Electronic Warfare Training under Complicated Electromagnetic Environment of the Object. Naval electronic warfare training should not only emphasize the commonality general training, also want to highlight the professional characteristic of electronic warfare in particular need to train for complex electromagnetic environment. According to different training objects, the surface ship ecm training can be divided into ${ }^{[7]}$ : wing commander, platform, commander, department officer training, technical officer (soldiers).

2 The Content of the Surface Warship Electronic Warfare Training under Complicated Electromagnetic Environment Settings. (1) Single ship (boat) tactical basic training

Main purpose is to popularize the basic theory of complex electromagnetic environment, master the basic knowledge of electronic warfare; In radar ew deployment exercises (boats), improve the individual to the operation of the ew equipment use and maintenance; Close all fighting positions 
and departments (contingent) and radar (boats) concerted action; The single ship (boat) have the basic ability of electronic warfare.

(2) The ship (boat) tactical training application

Is mainly to increase the trainees ew knowledge and practical skills, when preparing and implementing the operation correctly perform their duties; In a complex electromagnetic environment, enable trainees to correct and flexible use of electronic warfare troops and equipment; To explore the complex electromagnetic environment under the condition of electronic warfare methods. Are usually performed in a single ship (boat) technology tactics after basic training, can be divided into several topics, training topic selection according to the instructions, may take the actual situation to the selected task and forces, and for the subject content and technology tactical training weak links that exist in the basic training organization, training should include: the specific content of the platform commander (captain, vice-captain, captain, vice-captain, value more officer training and training department officers and noncommissioned officers (soldiers).

(3) The formation tactics and basic training

Under the complicated electromagnetic environment is mainly to the formation of electronic warfare YanLian, organize the implementation of procedures and methods for the formation under the complex electromagnetic environment of the basic electronic warfare capabilities. Including fleet commander and command post training, naval commander and command post training, department officers and noncommissioned officers (soldiers) training.

(4) Formation tactics application training

Fleet tactical application training is to further explore the tf, YanLian complex electromagnetic environment conditions of electronic warfare new methods; Improve the level of commander and command post personnel's electronic warfare tactics application; The formation without combat training can carries out of combat missions under complicated electromagnetic environment. Generally in the formation technology tactics based training tactical basis after training (technical), after can be divided into several topics, subject setting and selection according to the instructions from the superiors, could combat mission and the units of the actual situation to determine, for each subject can set different tactical training many times background, complex electromagnetic environment.

\section{Surface Ships under Complicated Electromagnetic Environment Electronic Warfare Training Ways and Methods}

1 Surface Ships Under Complicated Electromagnetic Environment the Main Way for Ecm Training. (1) Under complicated electromagnetic environment naval electronic warfare system training

Naval electronic warfare under complicated electromagnetic environment of the single system refers to the electronic warfare department training training alone, including personal and individual ew equipment general training and the overall system of the joint training. Its purpose is to improve the trainees for individual ew equipment of basic theory and basic operation skills, and electronic warfare system internal synergy between cooperate ability, and training for all electronic warfare system foundation, suitable for electronic warfare department authorized personnel of related equipment and the related training commanders.

(2) Under complicated electromagnetic environment related to electronic warfare system training

Related to electronic warfare under the complex electromagnetic environment is refers to the associated with electronic warfare system training including other departments synergy between all of the personnel, equipment, training. Mainly for electronic warfare department and closely related with navigation, missile weapons, naval gun, the water between coordination use, and the emc training. Ask trainees must have higher operational use frequency quality, commander must establish the idea of "using frequency is to fight".

2. Surface Ships Under Complicated Electromagnetic Environment the Main Way for Ecm Training. (1) Priority to with simulation training base in training 
Surface warship electronic warfare training under complicated electromagnetic environment affected by various natural environment, artificial environment and many other factors is bigger, such as natural environment and the future actual combat area are consistent, the enemy jamming equipment for the influence of weapons and equipment I use with their enemy jamming equipment simulation equipment we use is a consistent problem, the information security problems in training, etc., make us difficult to realize real the complex electromagnetic environment of the battlefield simulation, so that the training and actual combat may be produced.

Training base can eliminate the restriction factor; well field mainly JiaoLianShi, naval training center, training base and maritime contract proving ground, and colleges teaching, experimental sites, etc. These places can be according to the different training contents, training in complex electromagnetic environment object in construction, to meet the demands of training for ${ }^{[8]}$.

(2) In distributed interactive network system to support different training

Network training method, is refers to the use of information technology, computer network technology, in particular to simulate complex operational environment and combat process, a training method to raise the capacity of their forces. Distributed interactive network training, are distributed in different locations, independent of weapons and equipment system simulator and computer simulations of the combat simulation system linked, forming network warfare simulation system. Rely on distributed interactive network training, can put the different area of the ship unit together, don't even have to deliver real soldier live-fire, can in the compound, forces in anchorage ground (sea), under the background of the same think and fight, fight the homework on the net at the same time, can receive effect similar to large scale field exercises at sea.

After further development, if they could be formed by the distribution in different parts of the colleges and universities and ship unit composed of a variety of simulators and simulation system of synthetic army tactical training system network, and further development of distributed interactive combat training environment, make the soldiers from a single vessel to head all can participate in different levels of electronic warfare combat theory and electronic warfare equipment, electronic warfare training will be further improved.

(3) Priority to with real soldiers set up sea area of training

Give priority to with real soldiers set up sea area training refers to the actual shoulder the task of surface ship formation, specially built around a certain subject or topic background training environment (area) the organization of training. Real soldiers live-fire training enables trainees truly familiar with the performance of the weapon equipment, make the training and actual combat more press close to, promote the combination of people and weapons and equipment, improve the operational skills of the trainee, enhance the training effect. At the same time, in order to improve the force under complex electromagnetic environment of actual combat ability must also be in selected area can simulate the approximate real battlefield electromagnetic environment. This training method is applicable to military training has entered a higher stage, need a real soldier comprehensive live-fire drills and exercises, or to carry on the investigative practice.

\section{Conclusions}

Naval electronic warfare training mode, is to force the height of the ecm training rule generalization and summary, guiding the development direction of electronic warfare training. Intensify the study of the patterns of training and applied to the electronic warfare training, in practice, constantly improve and perfect, to make the ship electronic warfare operational capability continuously improve and jumped.

\section{References}

[1] Zhang Jing. The difficulties of the naval battle field complex electromagnetic environment build [J]. Information against academic, 2007. 
[2] yuan-yuan zheng, wang tao, Hou Zhiji. Network attack and defense training effect evaluation research study $[\mathrm{J}]$. Science, technology and engineering, 2006, (9)

[3] AnGong Deng Yang built, Lv Lianyuan. Integrated electronic warfare combat effectiveness simulation system research [J]. Computer simulation, 2002, (1) has 6.

[4] Zhang Wuqian. The future development trend of ew equipment [J]. Aerospace electronic countermeasures, 1998 (1): 58-61.

[5] Jiang Fang, chang-lin wang. Battlefield information and information [J]. Journal of national defense science and technology, 2002(2):67-68.

[6] Zhang Yaxue. The challenge for win strives for realism the innovation tamping foundation Focus on talent of education informatization armor technology $[\mathrm{J}]$. Journal of defense technology, 2004 (6):35-37.

[7] Li Yinhong. Electronic countermeasure team officers and soldiers training training methods study [J]. Journal of electronic countermeasures of academic, 2003(3):74-37.

[8] Zhou Shizhong. Foreign naval military training methods of the reform and development [J]. Journal of world naval training, 2005 (4). 